\title{
Atherosclerosis in systemic lupus erythematosus
}

\section{Sara Croca \\ saracroca@gmail.com}

Anisur Rahman

anisur.rahman@ucl.ac.uk

Centre for Rheumatology Research, Division of Medicine, University College London, Room 412 Rayne Institute, 5 University Street, London WC1E 6JF, United Kingdom

*Corresponding author.

\section{Abstract}

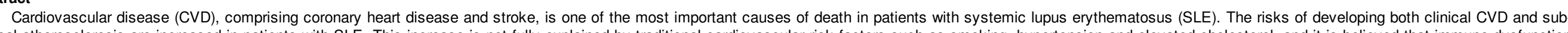

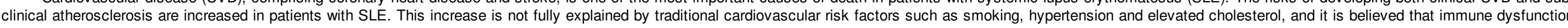

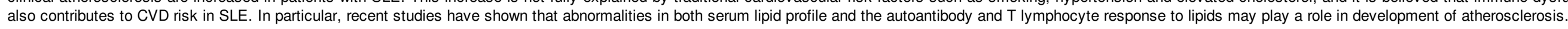

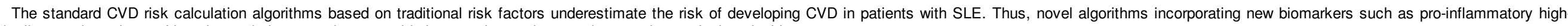
density lipoprotein and use of imaging techniques such as carotid ultrasound scanning may become increasingly valuable.

Keywords: Systemic lupus erythematosus; Cardiovascular disease; Atherosclerosis; Lipids; Risk stratification; Autoantibodies; Invariant natural killer T cells

\section{Introduction}

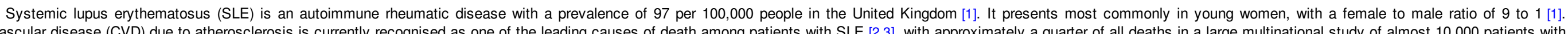

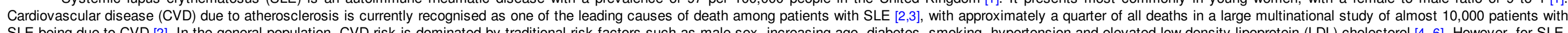

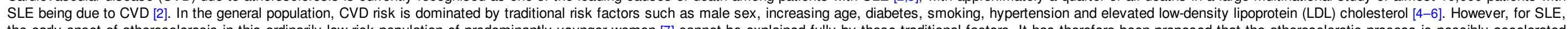

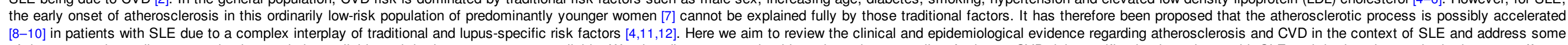

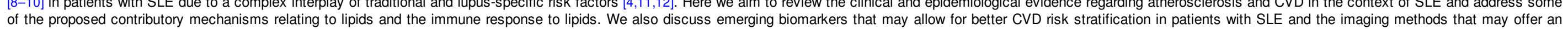
of the proposed contributory mechanisms relating to lipids and the immune resp
accurate assessment of the actual atherosclerotic burden of individual patients.

\section{Epidemiological and clinical evidence for the increased risk of CVD in patients with SLE}

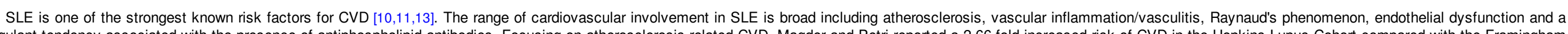

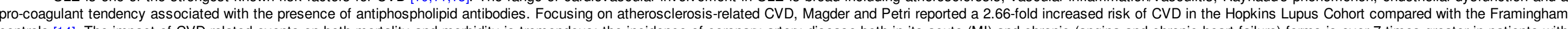

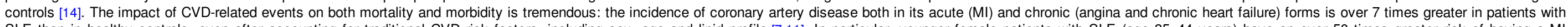

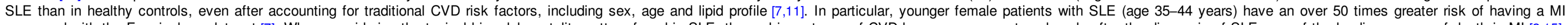

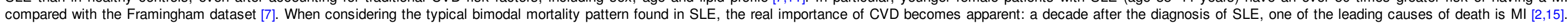
Patients with SLE also have a greater risk for stroke, with an overall prevalence that can reach 20\%, and high recurrence rate and greater mortality than matched controls [16,17].

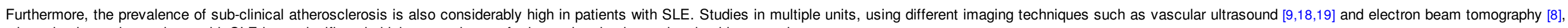
have consistently shown that patients with SLE have significantly higher prevalence of atherosclerotic plaque than healthy controls.

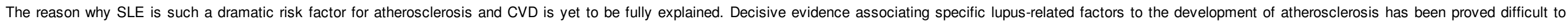

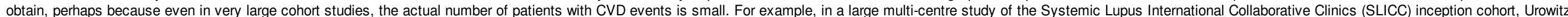

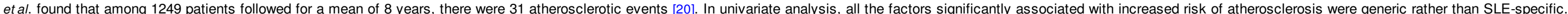
These included male gender, increased age, smoking, hypertension and family history of CVD, but in multi-variable analysis, only non-modifiable risk factors, namely age and male gender, remained significant [20]

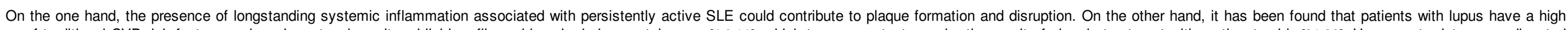

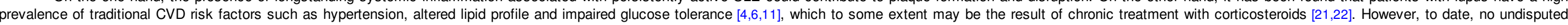

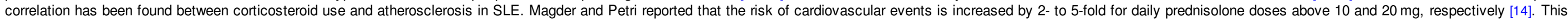

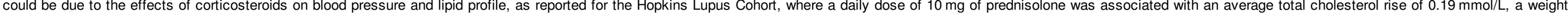

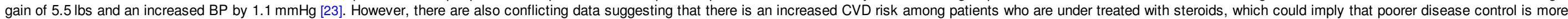
relevant in determining a higher CVD risk than steroid treatment per se [8].

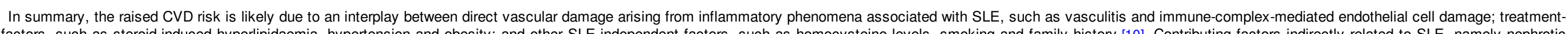

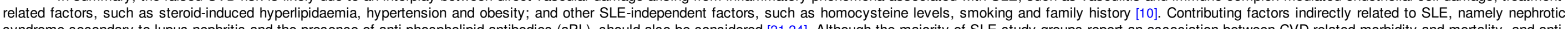

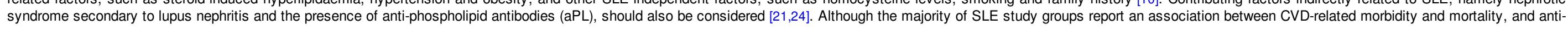




\section{ELSEVIER_YBERH_1274}

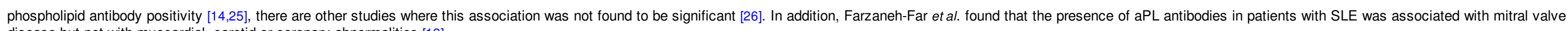
disease but not with myocardial, carotid or coronary abnormalities [19]

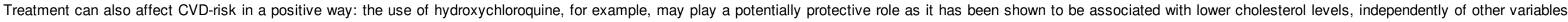

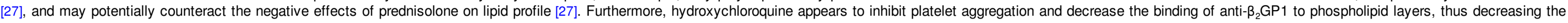
risk of thrombosis [28-30].

\section{Cardiovascular risk stratification in patients with SLE}

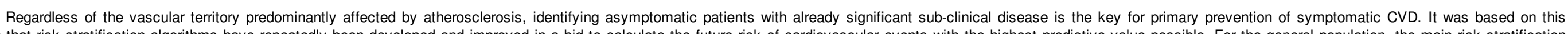

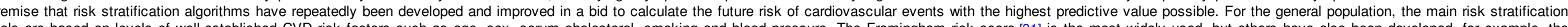

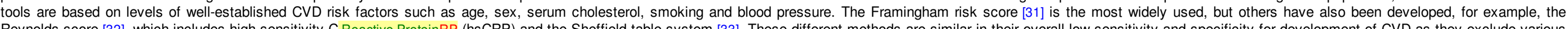

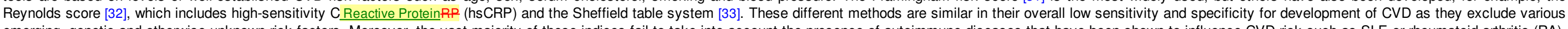

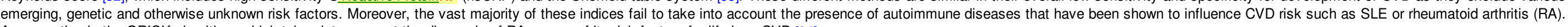
An exception is the QRISK algorithm, which takes into account the diagnosis of RA as one of its risk factors for life-long CVD [34].

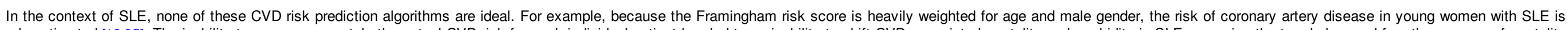

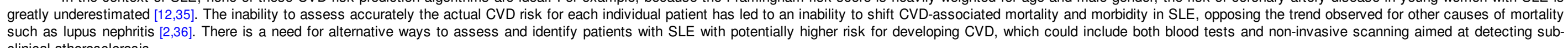
such as lupus nephritis
clinical atherosclerosis.

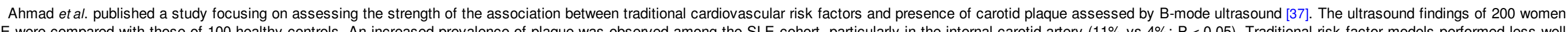

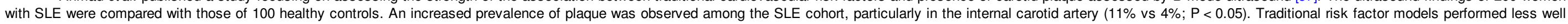
in SLE compared with controls, but when using a multivariable model, which included SLE-related factors (including azathioprine use and aPL), a significant performance improvement was noted.

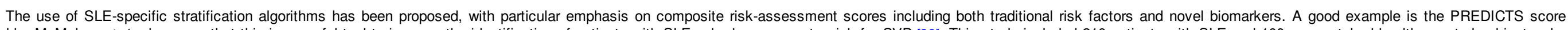

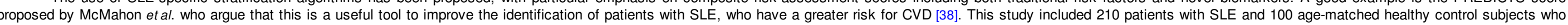

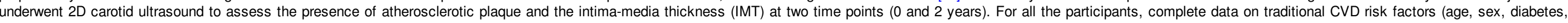

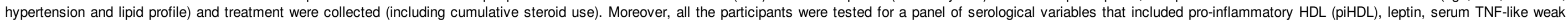

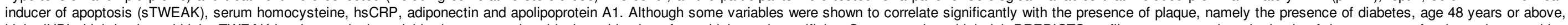

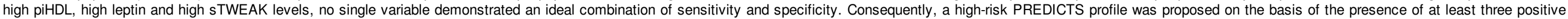

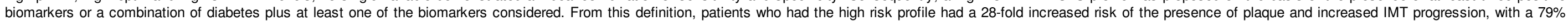
specificity and $89 \%$ sensitivity (negative predictive value $89 \%$ and positive predictive value $64 \%$ ) [38].

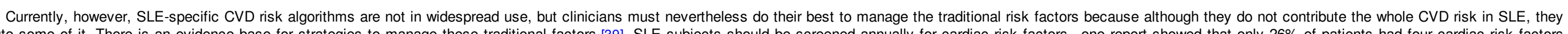

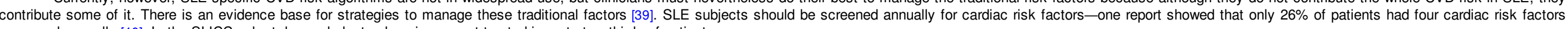
assessed annually [40]. In the SLICC cohort, hypercholesterolaemia was not treated in up to two-thirds of patients.

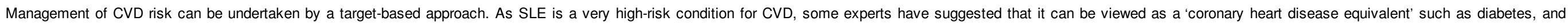
therefore, targets for hypertension and raised cholesterol should be adjusted accordingly [41].

\section{Abnormal lipids and increased atherosclerosis in SLE}

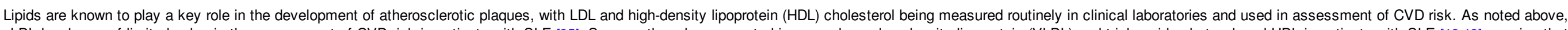

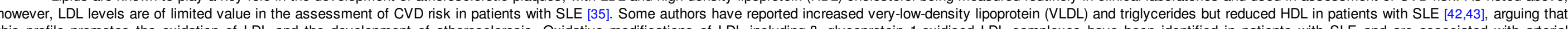

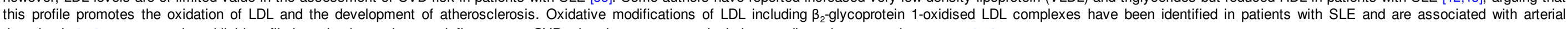
thrombosis [44]; moreover, altered lipid profile has also been shown to influence non-CVD related outcomes, particularly regarding adverse renal outcomes [45].

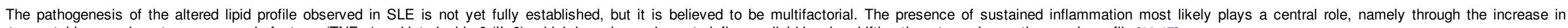
inflammatory cytokines such as tumour necrosis factor $\alpha$ (TNF $\alpha$ ) and interleukin 6 (IL-6), which have been shown to influence lipid levels, shifting them towards an atherogenic profile [46,47].

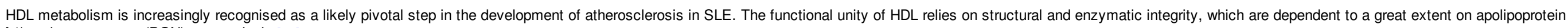
A1 (ApoA1) and paraoxonase (PON), respectively [48].

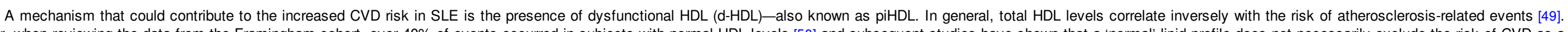

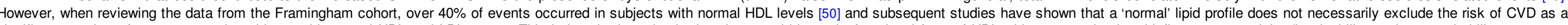

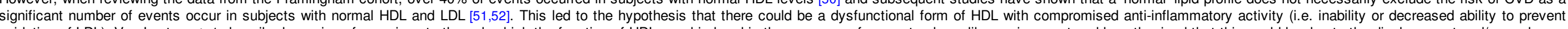

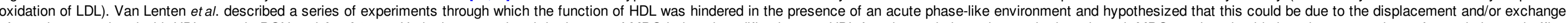

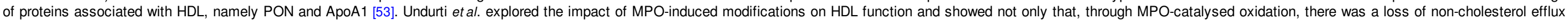

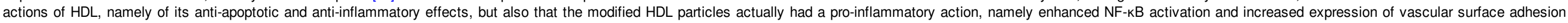

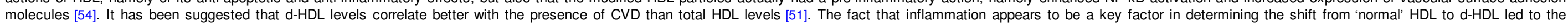

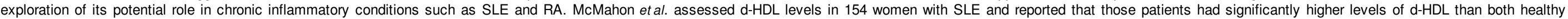

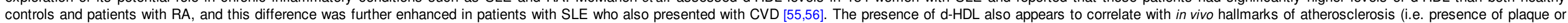

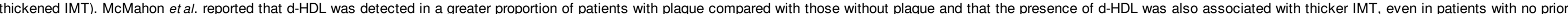




\section{Immune response to lipid and development of atherosclerosis in SLE}

Both the humoral and T cell response to lipids may be abnormal in patients with SLE, potentially contributing to the development of atherosclerosis.

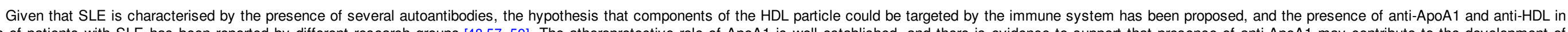

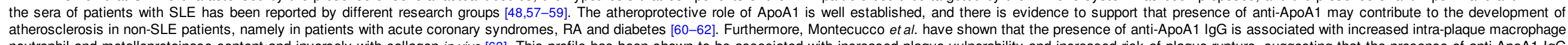

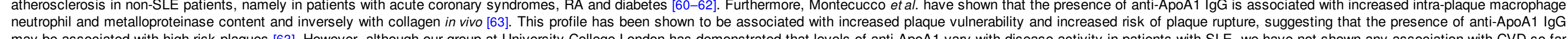

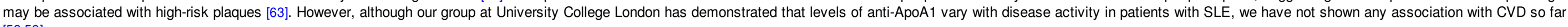
$[58,59]$.

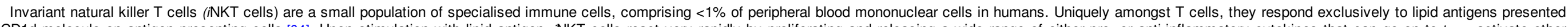

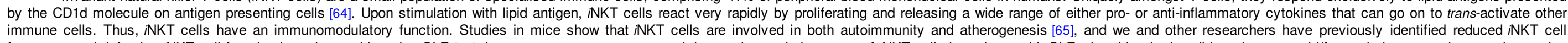

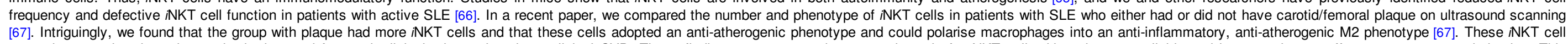

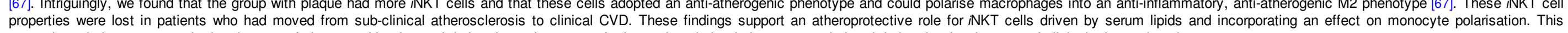
properties were lost in patients who had moved from sub-clinical atherosclerosis to clinical CVD. These findings support an atheroprotective role for iNKT cells driven by serum lipids and ir
protective role is not present in the absence of plaque and is triggered during the early stages of atherosclerosis but is lost or overwhelmed during the development of clinical atherosclerosis [67].

\section{Use of vascular imaging to assess atherosclerotic burden in patients with SLE}

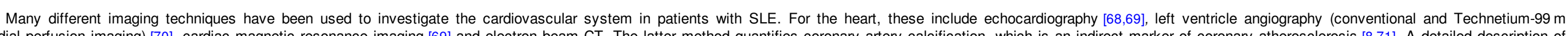

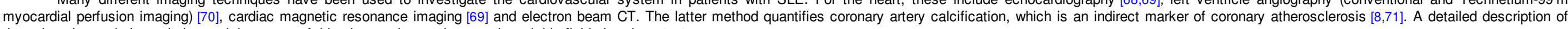
these imaging techniques is beyond the scope of this chapter, but we have reviewed this field elsewhere [72].

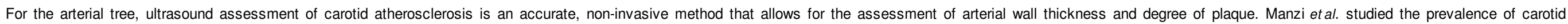

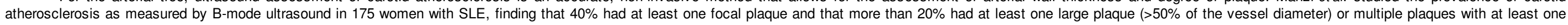

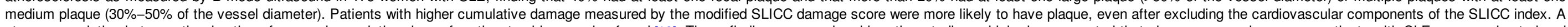

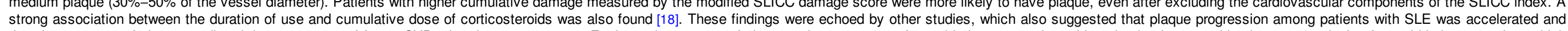

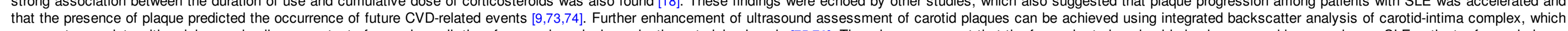

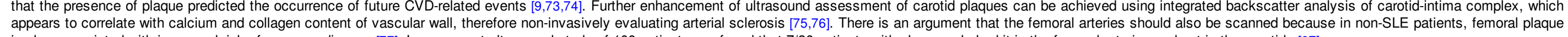
is also associated with increased risk of coronary disease [77]. In our recent ultrasound study of 100 patients, we found that 7/36 patients with plaque only had it in the femoral arteries and not in the carotids [67].

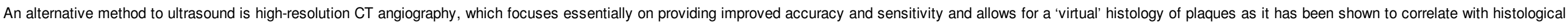
findings of atheromatous plaques at the carotid bifurcation [78]. However, limitations associated with the use of contrast and radiation exposure are of concern.

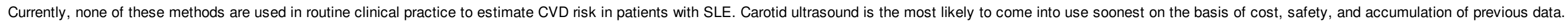

\section{Summary}

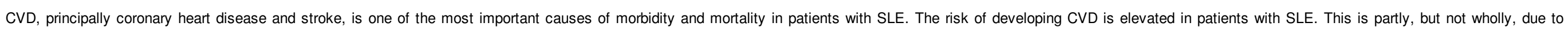

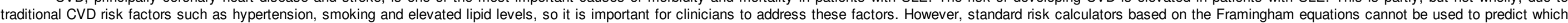

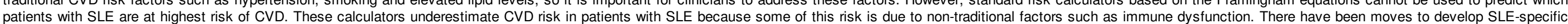

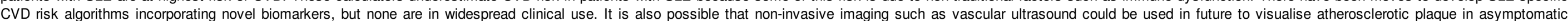
patients and thus guide the management of CVD risk.

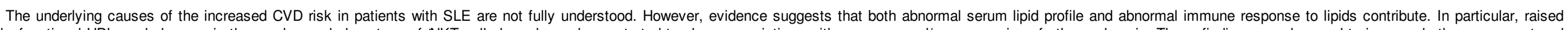

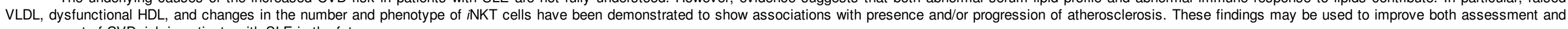
management of CVD risk in patients with SLE in the future.

\section{Practice points}

- Patients with SLE have an increased risk of developing CVD.

- It is important to consider whether smoking, diabetes, blood pressure and lipids are under optimal management in patients with SLE.

- However, the standard CVD risk calculation algorithms underestimate the risk in patients with SLE.

Research agenda

- It is important to develop SLE-specific CVD risk algorithms that include factors known to influence this risk in patients with SLE.

- Levels of VLDL and d-HDL may be important contributors to CVD risk in patients with SLE.

NKT cells appear to adopt an atheroprotective phenotype in patients with SLE and asymptomatic atherosclerotic plaque and lose this phenotype when CVD develops. Further experiments to understand this phenomenon are needed. 


\section{ELSEVIER_YBERH_1274}

\section{Conflict of interest}

Neither author has any conflicts of interest.

\section{Acknowledgements}

AR is supported by the National Institute for Health Research University College London Hospitals Biomedical Research Centre, but the Centre played no role in preparation of this manuscript.

\section{References}

[1]

F. Rees, M. Doherty, M. Grainge, et al., The incidence and prevalence of systemic lupus erythematosus in the UK, 1999-2012, Ann rheum Dis 75 (1), $2016,136-141$.

[2]

S. Bernatsky, J.F. Boivin, L. Joseph, et al., Mortality in systemic lupus erythematosus, Arthr Rheum $\mathbf{5 4}$ (8), 2006, 2550-2557.

[3]

G. Thomas, J. Mancini, N. Jourde-Chiche, et al., Mortality associated with systemic lupus erythematosus in France assessed by multiple-cause-of-death analysis, Arthr Rheumatol 66 (9), $2014,2503-2511$.

[4]

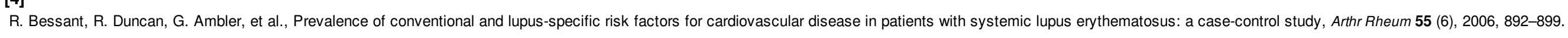

[5]

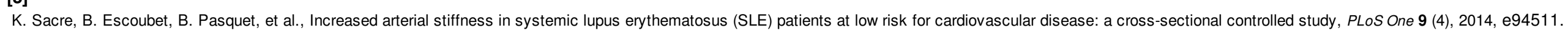

[6]

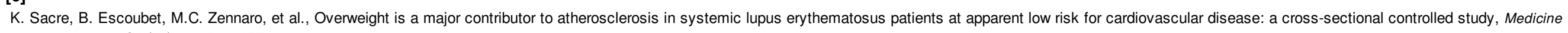
(Baltimore) 94 (48), 2015, e2177.

$* *[7]$

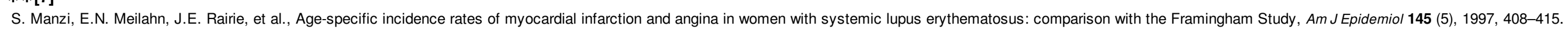
[8]

Y. Asanuma, A. Oeser, A.K. Shintani, et al., Premature coronary-artery atherosclerosis in systemic lupus erythematosus, N Engl J Med 349 (25), 2003, 2407-2415.

$* *[9]$

M.J. Roman, B.A. Shanker, A. Davis, et al., Prevalence and correlates of accelerated atherosclerosis in systemic lupus erythematosus, N Engl J Med 349 (25), 2003, $2399-2406$.

[10]

I.N. Bruce, 'Not only...but also': factors that contribute to accelerated atherosclerosis and premature coronary heart disease in systemic lupus erythematosus, Rheumatology (Oxford, England) 44 (12), 2005, 1492-1502.

[11]

J.M. Esdaile, M. Abrahamowicz, T. Grodzicky, et al., Traditional Framingham risk factors fail to fully account for accelerated atherosclerosis in systemic lupus erythematosus, Arthr Rheum 44 (10), $2001,2331-2337$.

[12]

R. Bessant, A. Hingorani, L. Patel, et al., Risk of coronary heart disease and stroke in a large British cohort of patients with systemic lupus erythematosus, Rheumatology (Oxford, England) 43 (7), 2004, 924-929.

[13]

P. Rahman, M.B. Urowitz, D.D. Gladman, et al., Contribution of traditional risk factors to coronary artery disease in patients with systemic lupus erythematosus, $J$ Rheumatol 26 (11), 1999, 2363-2368.

[14]

L.S. Magder and M. Petri, Incidence of and risk factors for adverse cardiovascular events among patients with systemic lupus erythematosus, Am J Epidemiol 176 (8), $2012,708-719$.

[15]

M. Abu-Shakra, M.B. Urowitz, D.D. Gladman and J. Gough, Mortality studies in systemic lupus erythematosus. Results from a single center. II. Predictor variables for mortality, J Rheumato/ 22 (7), 1995, 1265-1270.

[16]

Y. Kitagawa, F. Gotoh, A. Koto and H. Okayasu, Stroke in systemic lupus erythematosus, Stroke J Cereb circ 21 (11), 1990, 1533-1539. 


\section{ELSEVIER_YBERH_1274}

M. Holmqvist, J.F. Simard, K. Asplund and E.V. Arkema, Stroke in systemic lupus erythematosus: a meta-analysis of population-based cohort studies, RMD Open 1 (1), 2015 , e000168.

[18]

S. Manzi, F. Selzer, K. Sutton-Tyrrell, et al., Prevalence and risk factors of carotid plaque in women with systemic lupus erythematosus, Arthr Rheum 42 (1), $1999,51-60$.

[19]

A. Farzaneh-Far, M.J. Roman, M.D. Lockshin, et al., Relationship of antiphospholipid antibodies to cardiovascular manifestations of systemic lupus erythematosus, Arthr Rheum 54 (12), $2006,3918-3925$.

$* *[20]$

M.B. Urowitz, D. Gladman, D. Ibanez, et al., Atherosclerotic vascular events in a multinational inception cohort of systemic lupus erythematosus, Arthr care Res 62 (6), $2010,881-887$.

[21]

M. Petri, S. Perez-Gutthann, D. Spence and M.C. Hochberg, Risk factors for coronary artery disease in patients with systemic lupus erythematosus, Am J Med 93 (5), $1992,513-519$.

[22]

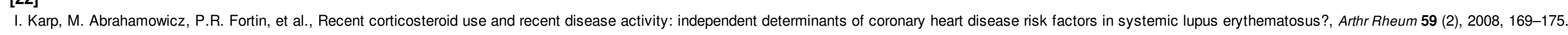

[23]

M. Petri, Detection of coronary artery disease and the role of traditional risk factors in the Hopkins Lupus Cohort, Lupus 9 (3), 2000, 170-175.

[24]

M. Petri, R. Roubenoff, G.E. Dallal, et al., Plasma homocysteine as a risk factor for atherothrombotic events in systemic lupus erythematosus, Lancet 348 (9035), 1996, 1120-1124.

[25]

S.M. Toloza, A.G. Uribe, G. McGwin, Jr., et al., Systemic lupus erythematosus in a multiethnic US cohort (LUMINA). XXIII. Baseline predictors of vascular events, Arthr Rheum 50 (12), $2004,3947-3957$.

[26]

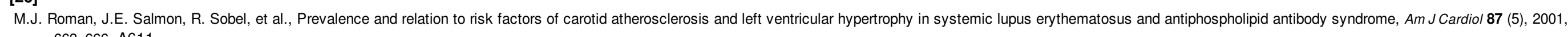
663-666, A611.

[27]

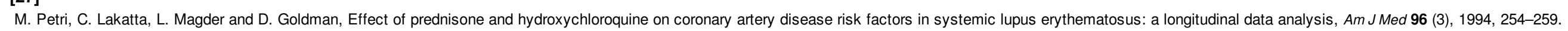

[28]

J.H. Rand, X.X. Wu, A.S. Quinn, et al., Hydroxychloroquine directly reduces the binding of antiphospholipid antibody-beta2-glycoprotein I complexes to phospholipid bilayers, Blood 112 (5), 2008, 1687-1695.

[29]

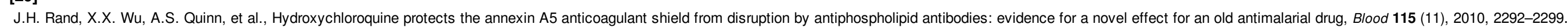

[30]

R.G. Espinola, S.S. Pierangeli, A.E. Gharavi and E.N. Harris, Hydroxychloroquine reverses platelet activation induced by human IgG antiphospholipid antibodies, Thromb haemost 87 (3), $2002,518-522$.

[31]

P.W. Wilson, R.B. D'Agostino, D. Levy, et al., Prediction of coronary heart disease using risk factor categories, Circulation 97 (18), 1998, $1837-1847$.

[32]

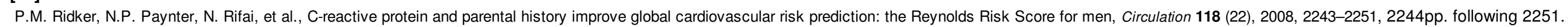

[33]

I.U. Haq, P.R. Jackson, W.W. Yeo and L.E. Ramsay, Sheffield risk and treatment table for cholesterol lowering for primary prevention of coronary heart disease, Lancet 346 (8988), $1995,1467-1471$.

[34]

J. Hippisley-Cox, C. Coupland, Y. Vinogradova, et al., Predicting cardiovascular risk in England and Wales: prospective derivation and validation of QRISK2, BMJ 336 (7659), 2008, 1475-1482.

[35]

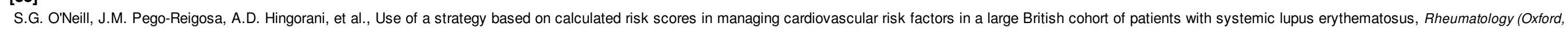
England) 48 (5), 2009, 573-575.

[36]

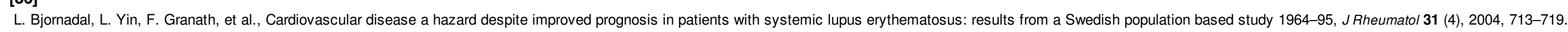




\section{ELSEVIER_YBERH_1274}

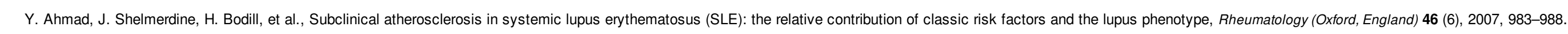

\section{$* *[38]$}

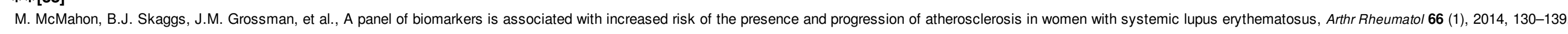
[39]

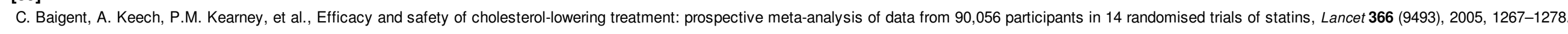

[40]

M. McMahon, B.H. Hahn and B.J. Skaggs, Systemic lupus erythematosus and cardiovascular disease: prediction and potential for therapeutic intervention, Expert Rev Clin Immunol 7 (2), $2011,227-241$.

[41]

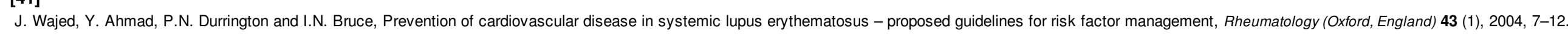

[42]

E.F. Borba and E. Bonfa, Dyslipoproteinemias in systemic lupus erythematosus: influence of disease, activity, and anticardiolipin antibodies, Lupus 6 (6), 1997, 533-539.

[43]

E.F. Borba, J.F. Carvalho and E. Bonfa, Mechanisms of dyslipoproteinemias in systemic lupus erythematosus, Clin Dev Immunol 13 (2-4), 2006, 203-208.

[44]

K. Kobayashi, M. Kishi, T. Atsumi, et al., Circulating oxidized LDL forms complexes with beta2-glycoprotein I: implication as an atherogenic autoantigen, J Lipid Res 44 (4), $2003,716-726$.

[45]

A. Tisseverasinghe, S. Lim, C. Greenwood, et al., Association between serum total cholesterol level and renal outcome in systemic lupus erythematosus, Arthr Rheum 54 (7), 2006, 2211-2219.

[46]

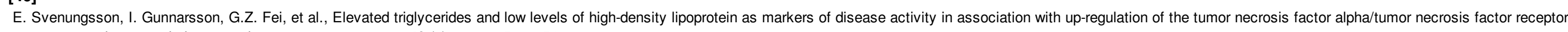
system in systemic lupus erythematosus, Arthr Rheum 48 (9), 2003, 2533-2540.

[47]

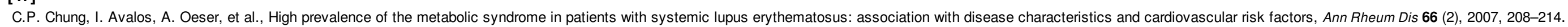

[48]

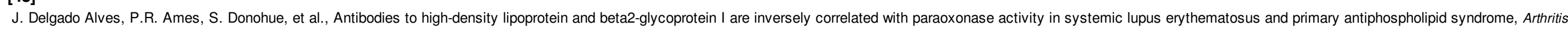
Rheum 46 (10), 2002, 2686-2694.

[49]

M. Navab, G.M. Anantharamaiah, S.T. Reddy, et al., Mechanisms of disease: proatherogenic HDL - an evolving field, Nat Clin Pract Endocrinol Metab 2 (9), 2006, 504-511.

[50]

T. Gordon, W.P. Castelli, M.C. Hjortland, et al., High density lipoprotein as a protective factor against coronary heart disease. The Framingham Study, Am J Med 62 (5), $1977,707-714$.

[51]

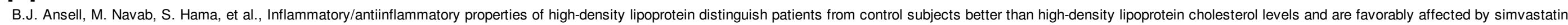
treatment, Circulation 108 (22), 2003, 2751-2756.

[52]

M. Navab, G.M. Ananthramaiah, S.T. Reddy, et al., The double jeopardy of HDL, Ann Med 37 (3), 2005, 173-178.

[53]

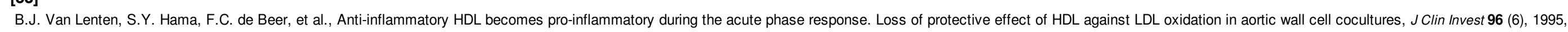
2758-2767.

[54]

A. Undurti, Y. Huang, J.A. Lupica, et al., Modification of high density lipoprotein by myeloperoxidase generates a pro-inflammatory particle, J Biol Chem 284 (45), 2009, $30825-30835$.

[55]

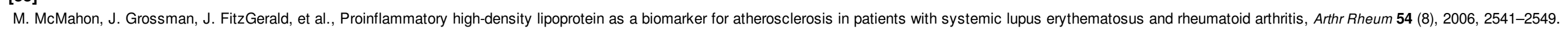




\section{ELSEVIER_YBERH_1274}

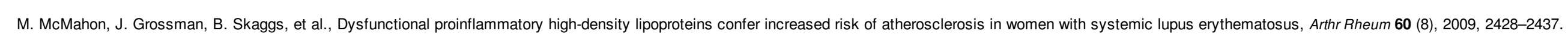
[57]

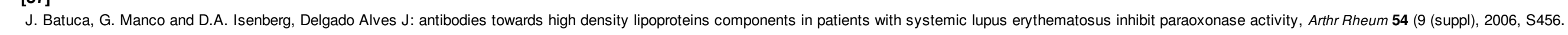
$* *$ [58]

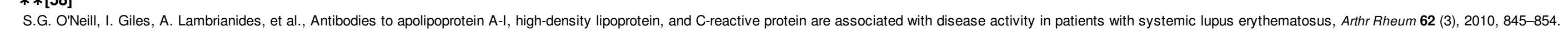
[59]

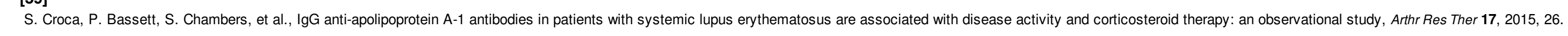
[60]

N. Vuilleumier, G. Reber, R. James, et al., Presence of autoantibodies to apolipoprotein A-1 in patients with acute coronary syndrome further links autoimmunity to cardiovascular disease, J Autoimmun 23 (4), $2004,353-360$.

[61]

S. Pagano, N. Satta, D. Werling, et al., Anti-apolipoprotein A-1 IgG in patients with myocardial infarction promotes inflammation through TLR2/CD14 complex, J Intern Med 272 (4), 2012, 344-357.

[62]

N. Vuilleumier, S. Bas, S. Pagano, et al., Anti-apolipoprotein A-1 IgG predicts major cardiovascular events in patients with rheumatoid arthritis, Arthr Rheum 62 (9), $2010,2640-2650$.

[63]

F. Montecucco, N. Vuilleumier, S. Pagano, et al., Anti-Apolipoprotein A-1 auto-antibodies are active mediators of atherosclerotic plaque vulnerability, Eur heart J 32 (4), $2011,412-421$.

[64]

S.P. Berzins, M.J. Smyth and A.G. Baxter, Presumed guilty: natural killer T cell defects and human disease, Nat Rev Immunol 11 (2), 2011, 131-142.

[65]

E. Tupin, A. Nicoletti, R. Elhage, et al., CD1d-dependent activation of NKT cells aggravates atherosclerosis, J Exp Med 199 (3), 2004, 417-422.

[66]

A. Bosma, A. Abdel-Gadir, D.A. Isenberg, et al., Lipid-antigen presentation by CD1d(+) B cells is essential for the maintenance of invariant natural killer T cells, Immunity $36(3), 2012,477-490$

\section{$* *[67]$}

E. Smith, S. Croca, K. Waddington, et al., Cross-talk between iNKT cells and monocytes triggers an atheroprotective immune response in SLE patients with asymptomatic plaque, Sci Immunol 1, 2016, eaah4081.

[68]

R. Maksimovic, P.M. Seferovic, A.D. Ristic, et al., Cardiac imaging in rheumatic diseases, Rheumatology (Oxford, England) 45 (Suppl 4), 2006, iv26-31.

[69]

S.G. O'Neill, S. Woldman, F. Bailliard, et al., Cardiac magnetic resonance imaging in patients with systemic lupus erythematosus, Ann Rheum Dis 68 (9), $2009,1478-1481$.

[70]

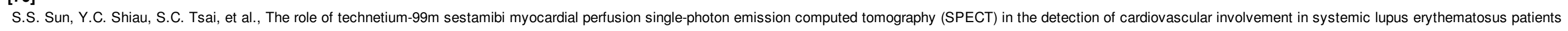
with non-specific chest complaints, Rheumatology (Oxford, England) $\mathbf{4 0}$ (10), 2001, 1106-1111.

[71]

A.N. Kiani, L. Magder and M. Petri, Coronary calcium in systemic lupus erythematosus is associated with traditional cardiovascular risk factors, but not with disease activity, $J$ Rheumato/ 35 (7), 2008, 1300-1306.

[72]

S.C. Croca and A. Rahman, Imaging assessment of cardiovascular disease in systemic lupus erythematosus, Clin Dev Immunol 2012, 2012, 694143.

[73]

T. Thompson, K. Sutton-Tyrrell, R.P. Wildman, et al., Progression of carotid intima-media thickness and plaque in women with systemic lupus erythematosus, Arthr Rheum 58 (3), 2008, 835-842.

$* *[74]$

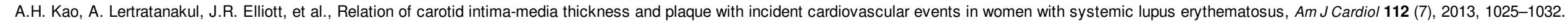
[75]

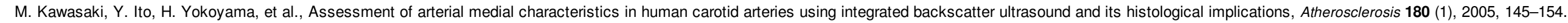




\section{ELSEVIER_YBERH_1274}

M. Rossi, M. Mosca, C. Tani, et al., Integrated backscatter analysis of carotid intima-media complex in patients with systemic lupus erythematosus, Clin Rheumatol 27 (12), $2008,1485-1488$. [77]

Z. Khoury, R. Schwartz, S. Gottlieb, et al., Relation of coronary artery disease to atherosclerotic disease in the aorta, carotid, and femoral arteries evaluated by ultrasound, Am J Cardiol 80 (11), 1997, 1429-1433. [78]

T.B. Oliver, G.A. Lammie, A.R. Wright, et al., Atherosclerotic plaque at the carotid bifurcation: CT angiographic appearance with histopathologic correlation, Ajnr 20 (5), $1999,897-901$. 